\title{
Vertical axis hybrid wind turbine design
}

\author{
Ersin Toptas ${ }^{1}$, Muharrem Ali Bayrak ${ }^{2}$, Talha Boz ${ }^{3}$ \\ Department of Mechatronics Engineering, Marmara University, Istanbul, Turkey \\ ${ }^{3}$ Corresponding author \\ E-mail: ${ }^{1}$ etoptas@marmara.edu.tr, ${ }^{2}$ bayrak.muharrem@gmail.com, ${ }^{3}$ talha.boz@marmara.edu.tr
}

Received 1 June 2020; accepted 26 June 2020

DOI https://doi.org/10.21595/jmai.2020.21508

Check for updates

Copyright (C) 2020 Ersin Toptas, et al. This is an open access article distributed under the Creative Commons Attribution License, which permits unrestricted use, distribution, and reproduction in any medium, provided the original work is properly cited.

\begin{abstract}
Wind energy is one of the alternative energy sources that respond positively to both global warming and energy needs, due to the increasing population density and the adverse effects it has brought in recent years. In this study, modification on current design of wind turbines has been demonstrated in order to increase the energy yield obtained from renewable wind energy sources. With the investigation of Turkey's wind map, a hybrid wind turbine design was carried out. This hybrid design incorporates Savonius and Darrieus type turbines which are used heavily in the literature. The hybrid design was developed to increase the performances of the vertical axis turbines from wind turbine types and to widen their usage areas. The comparison of the hybrid design with the conventional wind turbines were carried out by comparing their performance indexes such as efficiency, torque, and tip-speed ratio.
\end{abstract}

Keywords: design, turbine, energy, Savonius, Darrieus, FEA, hybrid.

\section{Introduction}

Energy is one of the most important needs that humanity has needed since its existence. In order to meet this energy demand, wind energy is one of the renewable energy solutions that decreases tackles the climate change phenomena. New designs are made to increase the performance of wind turbines and more energy recovery is tried to be achieved $[1,2]$. Wind turbines are divided into two groups, namely vertical and horizontal wind turbines. In investigating the efficiency of wind turbines, physical qualities such as Betz law, tip speed ratio, blade profile are used [2-4]. In Fig. 1, the relationships between the ratio of blade tip speed to wind speed $(\lambda)$ and power coefficient $\left(C_{p}\right)$ for different wind turbine types are given.

It is common to use vertical axis wind turbines in electrical energy production since their power coefficients are high. Different types of vertical wind turbines such as Savonius, Lafond, Darrieus and helical wind turbine are used and studied in the literature $[1,6]$. In a study on Savonius turbines, fixed wind focusers were used to increase its performance by focusing the wind. As a result of flow analysis, it was found that 6 guiding plates gave the best value [3]. In a study on Darrieus wind turbines, the effects of different blade types on performance were investigated by changing the angle of attack $[7,8]$. Then the effect of proximity of the wind blades on the performance was studied by changing the ratio of chord length-rotor diameter of a three-bladed vertical axis turbine. Power coefficients of a NACA 0018 airfoil with $0.3,0.6,0.8$ and 1.2 chord length-rotor diameter ratio were calculated. According to the results, the highest power coefficient value was 0.56 and it was with 0.8 chord length-rotor diameter ratio and 2.25 blade tip speed to wind ratio. The chord length-rotor diameter ratio, which performed well in the widest range, was found to be 0.3 .

Montero has developed a design that will create angle of attack that varies according to the angle of the blades of Darrieus turbines and aimed to achieve maximum efficiency in Darrieus turbines [9]. The design has achieved $30 \%$ efficiency even at $4-5 \mathrm{~m} / \mathrm{s}$ wind speeds that can be counted as low speed values $[9,10]$. Ahmedov worked on a hybrid design that combines the Savonius and Darrieus turbines [11]. However, its design did not go beyond putting together two separate types of turbines that are independent from each other. Nevertheless, the hybrid design that emerged has shown higher efficiency values in the experiments. 
In this study, vertical axis wind turbines that are used to benefit from wind energy are examined. A new hybrid wind turbine design has been developed in a way which combines the advantages of different wind turbine designs. In the turbine design, the aim was to increase both the power factor and the speed band where the turbine has high efficiency.

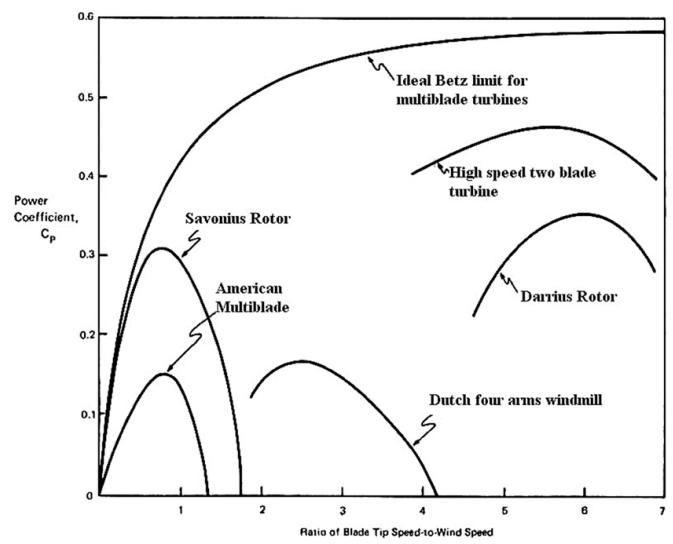

Fig. 1. Efficiency plot of wind turbines [5]

\section{Material and methods}

Low blade tip speed to wind speed ratio $(\lambda)$ in wind turbines means that not enough energy can be absorbed from the wind and therefore it has a low power coefficient. On the other hand, high blade tip speed to wind speed ratio causes high stresses on blades as well as low power coefficient. Therefore, it is very important to have the optimum blade tip speed to wind speed ratio to maximize efficiency.

Table 1. Ideal blade tip speed to wind speed ratio of wind turbines [5]

\begin{tabular}{|c|c|c|}
\hline Rotor type & Optimum $C_{p}$ & Range of tip-speed-to-wind-speed ratio \\
\hline Savonius & 0.3 & $0.8-0.85$ \\
\hline Dutch for arm & 0.14 & $2.0-3.0$ \\
\hline Darrieus & 0.32 & $5.5-6.5$ \\
\hline Two-blade & 0.43 & $4.5-6.5$ \\
\hline Propeller (ideal) & 0.55 & $3.0-7.0$ \\
\hline
\end{tabular}

In this study, a hybrid vertical wind turbine design that incorporates Savonius and Darrieus wind turbines has been introduced to increase performance. Performance indexes such as efficiency, torque, blade tip speed to wind speed ratio were compared with other turbines.

\subsection{Turbine design}

In the hybrid wind turbine design, internal wind turbine was chosen as Savonius and external wind turbine was chosen as Darrieus due to their blade tip speed to wind speed ratio values. Additionally, Darrieus wind turbine will increase the efficacy of Savonius wind turbine during low wind speeds. In order to find the optimum blade numbers for both wind turbine types, wind turbines with number of blades was designed. The designs of Savonius and Darrieus wind turbines with different wing numbers are shown in Fig. 2.

The hybrid design has been created by combining these two different wind turbines with $66 \%$ Savonius and $34 \%$ Darrieus turbine types. If the ratio of Savonius turbine increases, the efficiency will increase at relatively low speed values and decrease at high speed values. However, if the ratio of Darrieus increase, the efficiency rate will increase at high speed values and decrease at 
low speed values. In addition to the ratio between wind turbine types, the choice of blade profile to be used in these wind turbines is one of the main factors that determine the characteristics of the hybrid design. In this study, blackbird type blade profile has been chosen as turbine blades because it has a high camber value and low maximum thickness, reaching the highest lifting force at an angle of attack of $0^{\circ}$ and also contributing to the Savonius turbine by directing the wind at low wind speeds $[12,13]$. Fig. 3 shows the Blackbird blade profile selected for turbine blades in this study.

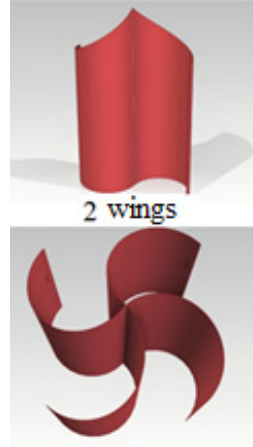

4 wings

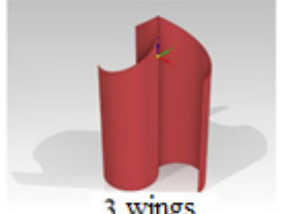

3 wings

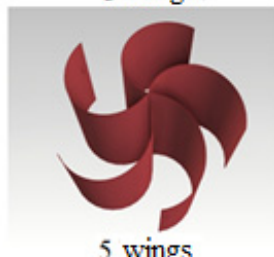

5 wings

a) Savonius

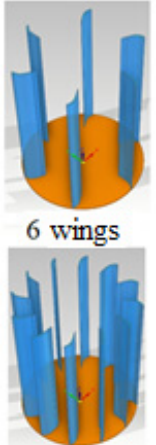

12 wings

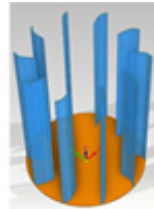

10 wings

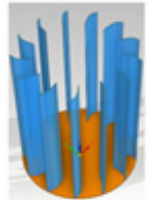

13 wings

b) Darrieus

Fig. 2. Design of Savonius and Darrieus turbine types with various blade numbers

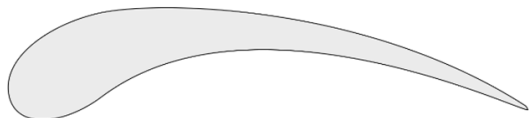

Fig. 3. Blackbird blade profile [13]

Wind focuser is the part that increases the power generation from the turbines by gathering the air flow to a narrower area and increasing the wind speed and pressure. In this study, it is aimed to increase the power of the turbine by adding wind focusers to the floor and ceiling of the turbine between the orange colored structures seen above and below the turbine as seen in Fig. 4.

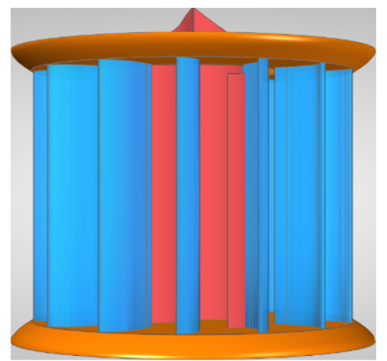

Fig. 4. Side view of hybrid wind turbine design

\subsection{Flow analysis}

Modules of two different programs have been used for analysis of hybrid wind turbine design. Models used in this study were ANSYS CFX and Solidworks Flow Simulation. Solidworks Flow Simulation was used for determining optimal number of turbine blades whereas calculation of parameters such as turbine efficiency and blade profile were realized through ANSYS CFX. Initial analyses were carried out for each parameter for wind speed of $5 \mathrm{~m} / \mathrm{s}$. Afterwards, in order to find the most efficient structure, ten different analyses were carried out by running the simulation with different wind speeds from $1 \mathrm{~m} / \mathrm{s}$ to $10 \mathrm{~m} / \mathrm{s}$ in intervals of $1 \mathrm{~m} / \mathrm{s}$. 
In this study, air was selected as the fluid in the analysis programs, and both laminar and turbulent flow types were chosen. The main performance parameter calculated in the analysis of Savonius and Darrieus blades is the pressure difference created by the wind on the turbine. Pressure difference was calculated for Savonius wind turbines with 2, 3, 4 and 5 blades and for Darrieus wind turbines with 6,10,12 and 13 blades. The speed of the wind was given as $5 \mathrm{~m} / \mathrm{s}$. Following the simulations, pressure graph was created according to the turbine angle. Parameters used in simulation using Solidworks Flow Simulation is shown in Fig. 5.
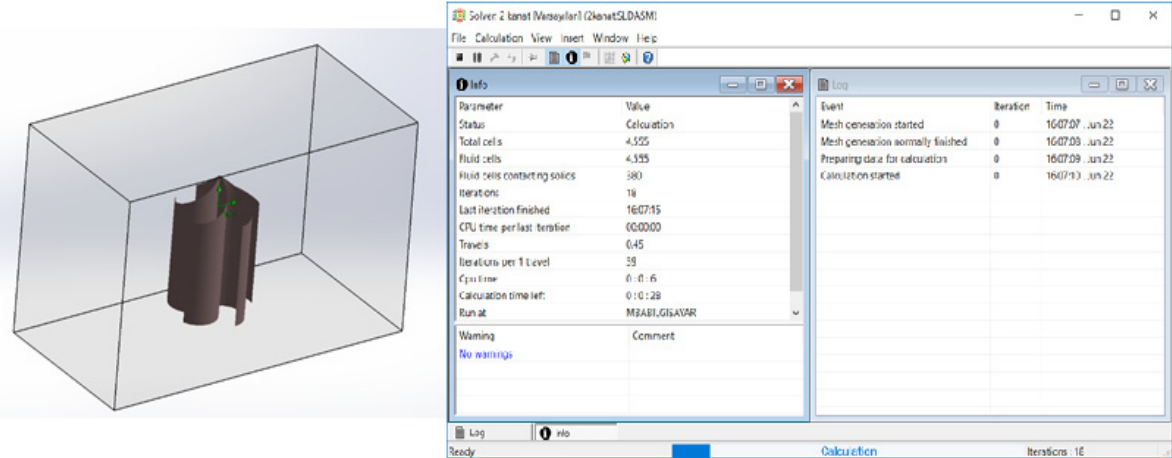

Fig. 5. Simulation parameters of Solidworks flow simulation

After determining the number of blades for both Savonius and Darrieus wind turbines in Solidworks, hybrid wind turbine design was analysed in ANSYS with calculation of torque generated with the turbine and creation of PowerN function that calculates the power output according to moment. The model preparation, parameters and rotor power outputs in ANSYS CFX is given in Fig. 6.

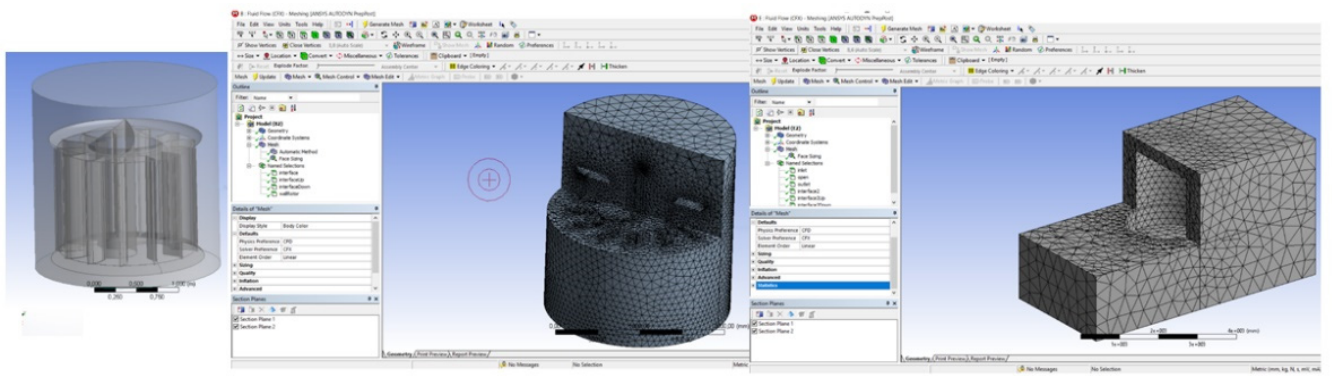

a) Preparation of the model in ANSYS CFX

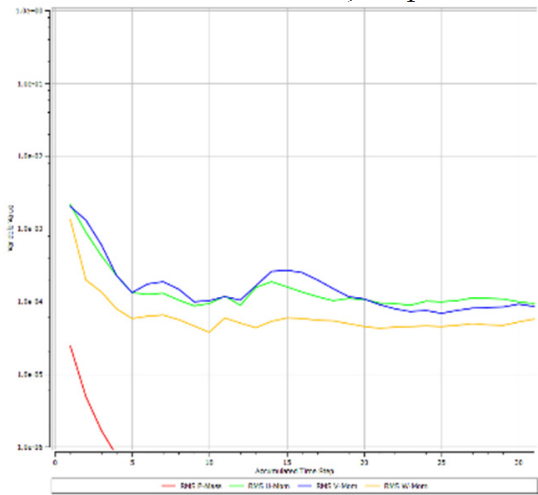

b) CFX solution and parameters

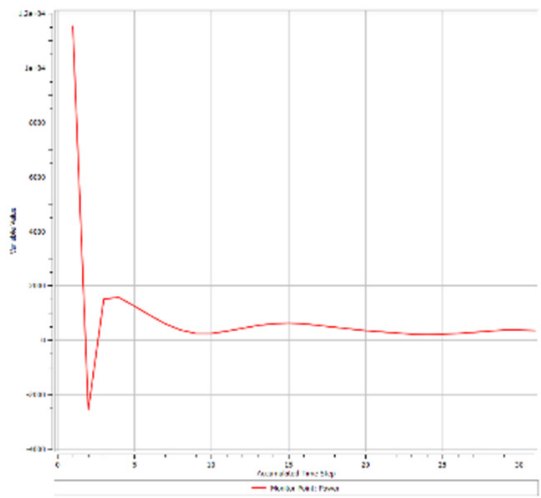

c) During solution rotor power output

Fig. 6. Flow analysis in ANSYS CFX 


\section{Results and discussion}

In the hybrid vertical wind tribune design, the number of blades was determined by first studying on Savonius and Darrieus wind turbines separately. Then by using the results of these simulations, a hybrid wind turbine design was created. In the simulation of Savonius wind turbine, the turbine with the three blades gave the maximum pressure difference with a $5 \mathrm{~m} / \mathrm{s}$ side wind. In Fig. 7, the pressure difference heatmap for two, three, four and five blade Savonius wind turbines are given. The pressure values for these turbines are given in Fig. 8 .

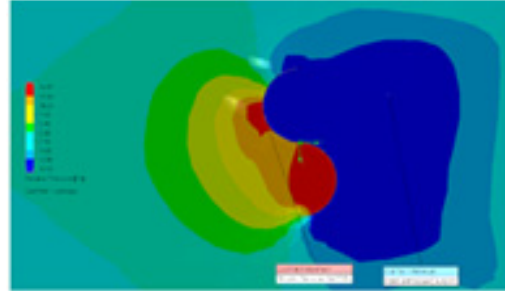

a) a-2 wing

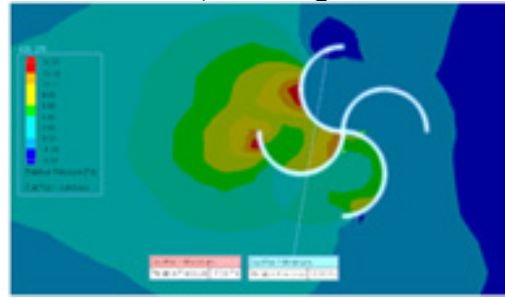

c) c-4 wings

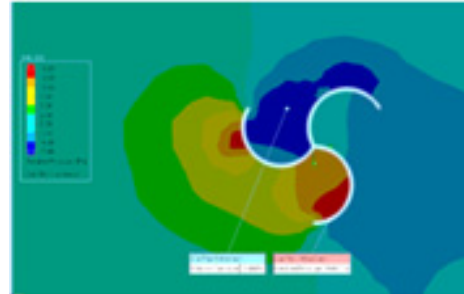

b) b-3 wings

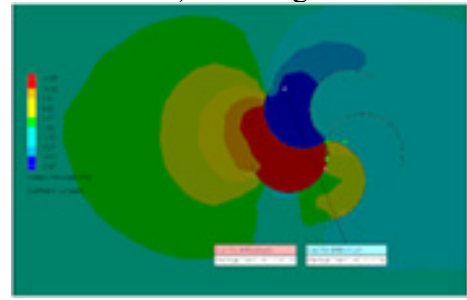

d) d-5 wings

Fig. 7. Savonius turbine CFX analysis results

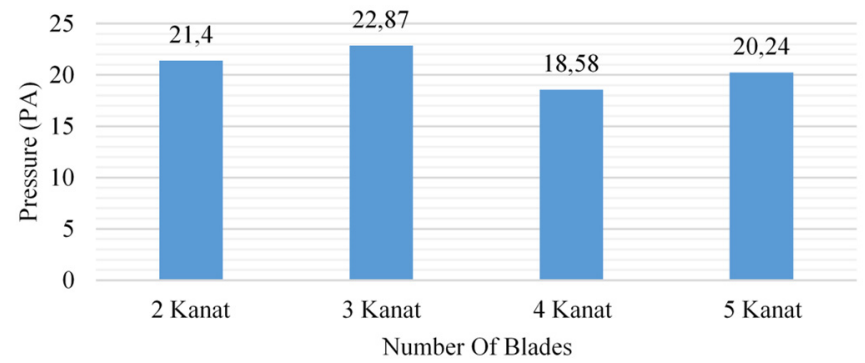

Fig. 8. Pressure differences arising on the Savonius turbine with $5 \mathrm{~m} / \mathrm{s}$ side wind

As a result of flow analysis on Savonius blades, it has been observed that the use of three blades is more efficient than standard two blades. This result is also supported by the findings of Aymane [13]. In line with these results, three number of blades was chosen as the Savonius part of the hybrid wind turbine design in this study since the production cost and complication was lower and the performance graph was higher.

In the same way as determining the number of Savonius blades, Darrieus wind turbines with different number of blades were analyzed with ANSYS CFX. As a result of these analyses, the most appropriate number of blades for Darrieus part of the hybrid wind turbine design was found. In Fig. 9, the pressure difference heatmap for six, eight, ten, twelve, thirteen and fourteen blade Darrieus wind turbines are given. The pressure values for these turbines are given in Fig. 10. 


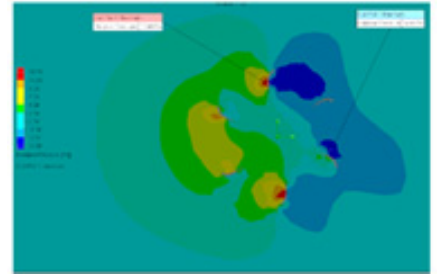

a) a-6 wing

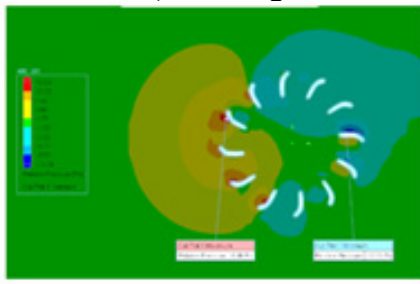

c) d-12 wings

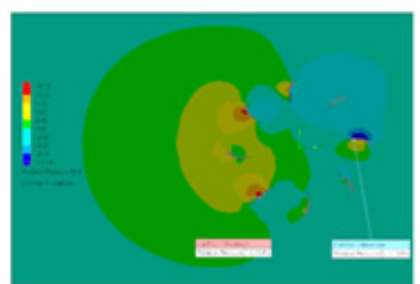

b) b-8 wings

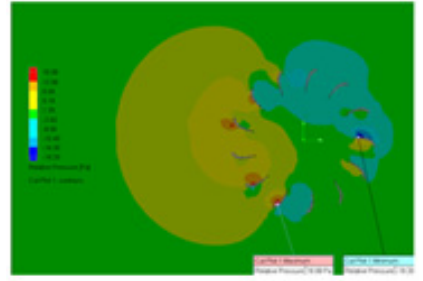

d) e-13 wings

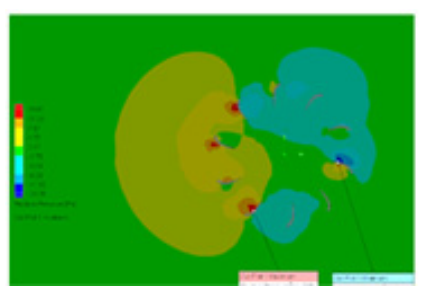

c) c-10 wings

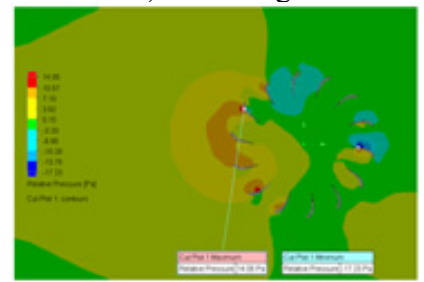

f) f-14 wings

Fig. 9. Darrieus turbine CFX analysis results

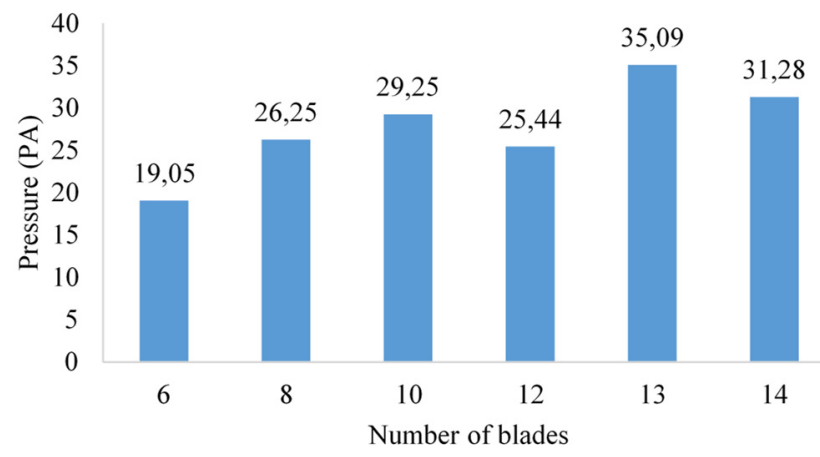

Fig. 10. Pressure difference graph based on the number of blades for Darrieus turbine

The results show that thirteen number of blades gives the highest-pressure difference in Darrieus wind turbine. Similar to these results, Vortexis brand wind turbines on the market support this assertion because they are also designed with thirteen blades [14]. The number of blades were not increased further because addition of blades to the design causes increase in cost and complication in manufacturing. Therefore, thirteen blades were chosen as the Darrieus part of the hybrid wind turbine design in this study.

After determining the number of blades for both Savonius and Darrieus wind turbines, a hybrid wind turbine which has three blade Savonius turbine inside and thirteen blade Darrieus turbine outside was analyzed in ANSYS CFX with $8 \mathrm{~m} / \mathrm{s}$ wind speed. Power output versus angle of the turbine of the hybrid wind design is given in Fig. 11.

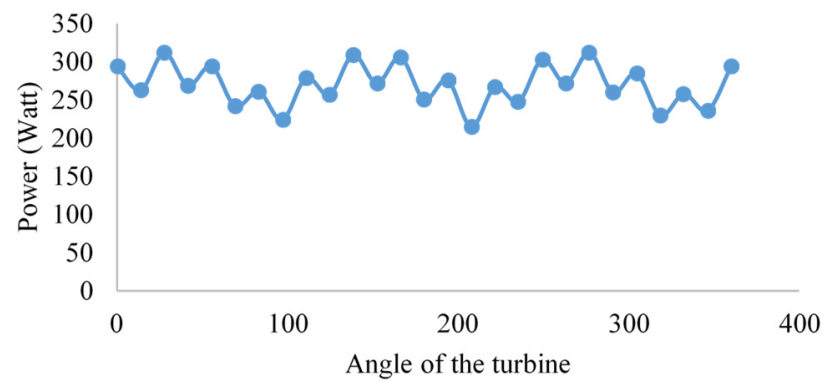

Fig. 11. Turbine power output for $8 \mathrm{~m} / \mathrm{s}$ wind speed 
Analysis showed that the designed hybrid wind turbine produced by an average of 270 Watts with $8 \mathrm{~m} / \mathrm{s}$. The generated power is calculated with Eq. (1). In calculating the efficiency of a turbine, the density $(\rho)$ of the air, the speed of the wind $(V)$, the power coefficient $\left(C_{p}\right)$, which is the ratio of the turbine propeller to the shaft power, and the rotor sweep area $(A)$ formed by the full turn of a blade are used. The efficiency of the designed hybrid wind turbine was calculated as $38.79 \%$ :

$P=\frac{1}{2} * \rho * V * C_{p} * A$

\section{Conclusions}

In this study, it is aimed to design a vertical hybrid wind turbine with Savonius and Darrieus wind turbines. In the first stage, analyses were made for both Savonius and Darrieus wind turbines taking into consideration the efficiency and production costs and the number of blades were selected according to the results of these analyses. The hybrid wind turbine design has three blade Savonius wind turbine inside and thirteen blade Darrieus blade outside. Then, the analysis of the hybrid wind turbine was carried out with $8 \mathrm{~m} / \mathrm{s}$ wind speed. In these analyses, it was seen that a efficiency of approximately $38 \%$ was reached. In addition to these results, it has been found that the use of wind focusers contributes to $8 \%$ energy production in hybrid wind turbine design.

In Fig. 13, the hybrid wind turbine design in this study is shown in comparison to the conventional wind turbines. As can be seen from the figure, the hybrid turbine design has efficiency value that is close to the highest efficiency values for both Savonius and Darrieus wind turbines.

In future work, it is necessary to perform the analysis of the hybrid wind turbine at different wind speeds and draw the pressure efficiency graph. It is also aimed to prepare a prototype of the designed wind turbine and conduct detailed performance tests in the wind tunnel. Thus, the real-world results of this hybrid wind turbine design can be compared with the results obtained from the simulations of the design in the virtual environment.

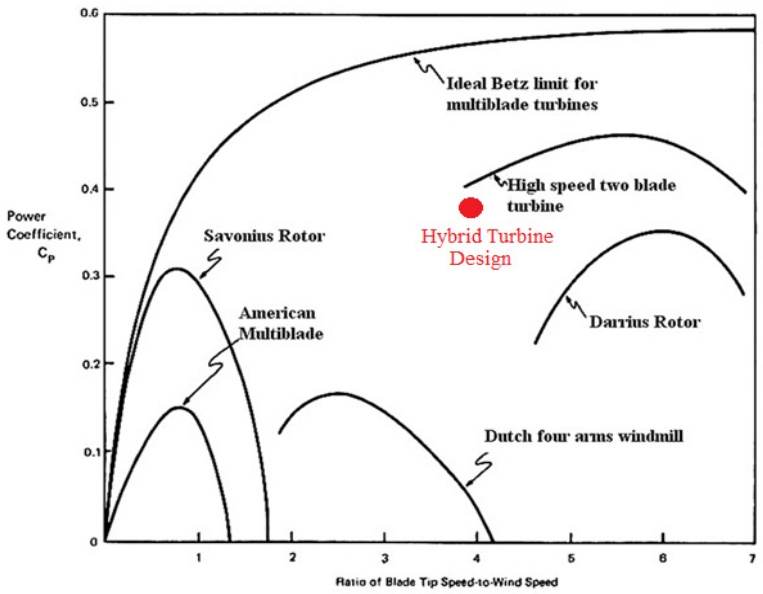

Fig. 13. The placement of the hybrid turbine design in efficiency graph

\section{References}

[1] Gutiérrez T. J., Sánchez C. P., Ovalle M. D. Design and simulation of controllers for a horizontal axis wind turbine. IEEE 4th Colombian Conference on Automatic Control (CCAC), 2019.

[2] Rachman A., Pratiwi P., Ashari L. Design and performance horizontal axis wind turbine taper type. Jurnal Teknik Mesin (JTM), Vol. 9, Issue 2, 2019, p. 58-63. 
[3] Gul I., Kolip A. Parça kanatlı savonius rüzgâr türbin performansının incelenmesi. El-Cezeri Journal of Science and Engineering, Vol. 5, Issue 3, 2018, p. 827-816.

[4] Chiarelli M. R., Massai A., Atzeni D., Bianco F. A New configuration of vertical axis wind turbine: an overview on efficiency and dynamic behavior. Journal of Energy Challenges and Mechanics, Vol. 2, Issue 1, 2015, p. 23-28.

[5] Karskarsdóttir M. A General Description and Comparison of Horizontal Axis Wind Turbines and Vertical Axis Wind Turbines. Ph.D. Thesis, University of Iceland, Iceland, 2014.

[6] Akkus N., Toptas E., Topal O. Thermomechanical analysis of arc welded joint by finite element method. International Congress on Advances in Welding Science and Technology for Construction, Energy and Transportation Systems, 2011.

[7] Majid A. Numerical Investigation of the Effect of the Blade Type and the Chord Length on the Performance of the Vertical Axis Wind Turbines. Ph.D. Thesis, Dokuz Eylul University, Turkey, 2015.

[8] Toptaş E., Akkus N. Damage detection of carbon fibers in filament winding machines using an electrical resistance method. The International Journal of Advanced Manufacturing Technology, Vol. 93, Issues 1-4, 2017, p. 671-679.

[9] Montero M. M. Optimization of Cyclic Pitch Control for a Vertical Axis Wind Turbine. Ph.D. Thesis, Delft University of Technology, Netherlands, 2017.

[10] Atasoy A., Toptas E., Kuchimov S., Kaplanoglu E., Takka S., Ozkan M. SMA actuated prosthetic finger design. 20th National Biomedical Engineering Meeting, 2016.

[11] Ahmedow A. S. Investigation of the Performance of a Hybrid Wind Turbine Darrieus-Savonius. Ph.D. Thesis, Loughborough University, UK, 2015.

[12] Pope K., Dincer I., Naterer G. Energy and exergy efficiency comparison of horizontal and vertical axis wind turbines. Renewable Energy, Vol. 35, Issue 9, 2010, p. 2102-2113.

[13] Aymane E. Savonius Vertical Wind Turbine: Design, Simulation, And Physical Testing. Ph.D. Thesis, Al Akhawayn Univercity, Morocco, 2017.

[14] Le Gouriérès D. Wind Power Plants, Theory and Design. Pergamon Press, Oxford, 1982.

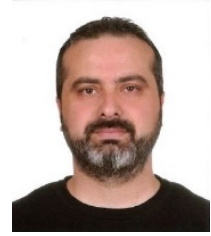

Ersin Toptas received Ph.D. degree in Institute of Pure and Applied Sciences from Marmara University, Istanbul, Turkey, in 2015. Now at the Faculty of Technology of Marmara University. His current research interests are mechanical design, computer aided analysis, SMA and composites.

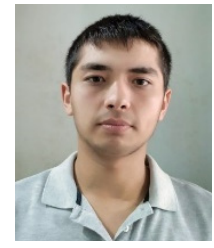

Muharrem Ali Albayrak was born in 1987 in Istanbul. He graduated from Marmara University Technology Faculty Mechatronics Engineering department in 2019. He is currently working as an engineer in a private company.

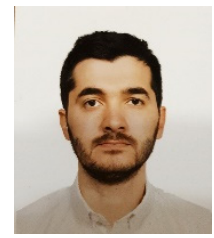

Talha Boz received M.Sc. degree in Institute of Pure and Applied Sciences from Sabanci University, Istanbul, Turkey, in 2012. He is a Ph.D. candidate for Mechatronics Engineering in Yildiz Technical University, Istanbul. He currently works as a research assistant in Marmara University, Istanbul. His current research interests are system dynamics and control, robotics and simulation of dynamic systems. 